\title{
Bio-Psychologically Based Resilience Traits in a Group of Healthy Undergraduate Students: The Role of NRG1 Gene
}

\author{
Zsuzsanna Elek ${ }^{1}$, Zsolt Rónai ${ }^{1}$, János Réthelyi ${ }^{2}$, Enikö Csilla Kiss ${ }^{3}$, István Tiringer, Ernö Hupuczi ${ }^{4}$, \\ László Martin ${ }^{5}$, János Kállai ${ }^{*}$
}

${ }^{1}$ Department of Medical Chemistry, Molecular Biology and Pathobiochemistry, Semmelweis University, Hungary

${ }^{2}$ Department of Psychiatry and Psychotherapy, Semmelweis University, Hungary

${ }^{3}$ Institute of Psychology, Faculty of Humanities, University of Pécs, Hungary

${ }^{4}$ Institute of Behavioral Sciences, Medical School, University of Pécs, Hungary

${ }^{5}$ Department of Pedagogy and Psychology, Kaposvar University, Hungary

*Corresponding author: Janos Kallai, Institute of Behavioral Sciences, Medical School, University of Pécs, Szigeti út 12, Pécs 7625, Hungary, Tel: +36-72-536-257

\section{Abstract}

Introduction and aims: The genetic predisposition for the psychological resilience has an essential role in the phenotype of adaptive and successful behavior, but the functional repertoire of bio-psychological bases for the adaptive personality growth is until uncompleted. Besides dopaminergic and serotoninergic system-related genes is required to reveal a new genetic target for understanding the potential biological mechanism of resilience. The object of this study was to examine the role of different genetic polymorphisms in adaptive and maladaptive personality traits. The rate of self-reported resilience and schizotypy trait scores were compared with the presence of homo- or heterozygote bases pairs in a set of single-nucleotide polymorphism (SNPs).

Participants: In the study participated 347 Caucasian graduate and postgraduate students who administered trait measure resilience, schizotypy, anxiousness and self-esteem questionnaires. In the same session all participants were asked to provide a DNS sample for genotyping the next SNPs: DRD2 (rs6277, rs1076560), RGS4 (rs2661319), COMPT (rs4680), HTR1B (rs13212041) further NRG1 (rs10503920), DTNBP1 (rs760761), and MIR137 (rs2660304) were the objects of the genotype and endophenotype traits examination study.

Results and conclusion: The NRG1 gene's rs10503920 polymorphism is advantageous in the evolution of the resilience endophenotype, where the tenacity, the goal-directed behavior, the maintained cognitive and affective self- control under stress and fast mental and physical recovery to the successful growth trajectory are the main stable components in the resilience traits pattern.
\end{abstract}

\section{Keywords}

Adversity, Endophenotype, Executive functions, Resilience, rs10503920, Self-esteem, SNP, tenacity

\section{Introduction}

The term resilience implies cognitive-emotional processes for coping with adverse events without harmful developmental consequences. This process advantageous for the personal growth and enhances the capability to be stable and successful in goal receiving and spatial and temporal behavioral organization for life strategies relatively independently from the environmental difficulties. Psychological resilience considered as a comprehensive automatic behavior organization system, a developmental pathway that involves attitudes, values, integrated personalized life strategy and habits $[1,2]$. In spite of the major role of resilience in personal growth, the biological roots of this behavior regulation system have remained in shadow. The neurobiological markers and the genetic contribution of the phenotype of resilience traits have not yet been exactly articulated. In this study focused on analysis one of a group of genetic polymorphism that may be a new agent in the formation of the resilience endophenotype.

Citation: Elek Z, Rónai Z, Réthelyi J, Kiss E C, Tiringer I, Hupuczi E, et al. (2020) Bio-Psychologically Based Resilience Traits in a Group of Healthy Undergraduate Students: The Role of NRG1 Gene. Int J Cogn Behav 3:006. doi.org/10.23937/2690-3172/1710006

Accepted: July 23, 2020; Published: July 25, 2020

Copyright: (C) 2020 Elek Z, et al. This is an open-access article distributed under the terms of the Creative Commons Attribution License, which permits unrestricted use, distribution, and reproduction in any medium, provided the original author and source are credited. 


\section{Resilience}

The resilience is a multidimensional competency to cope with biological and psychosocial vulnerabilities to chronic or acute traumas and illnesses and other adversity $[3,4]$. In a developmental point of view, resilience involves self-regulation and defending styles for a long-term life developmental period [5]. Individuals with high resilience showed adequate coping and adaptive response to stressful life events, low susceptibility to stress-related psychopathology, and have secure attachment and more positive emotions, and elevated openness toward unusual experiences comparing non-resilient participants [6-8]. However, low degree resilience associated with mood disorders, anxiety and negative emotions [9]. The resilience consists of several learned social traits $[10,11]$, but most of them associated with mental and physical recovery ability to healthy functions after receiving chronic or acute stress or adverse events [12], affective states, genetic predispositions [13], biological [14], social [15] and environmental factors [16]. The diverse areas of the resilience namely, trait resilience [17], process model of resilience [18] or outcome after experienced adversity model of resilience [10] can be integrated in a multidimensional model of resilience [2]. There are more methods available to measure the resilience $[19,20]$. The present study focuses on the association for the genetic predispositions and several trait components of resilience. One most valid and reliable method to measure the trait resilience is the Connor-Davidson Resilience Scale, (CD-RISC, 2003) that has been translated more than 50 languages and administered in lots of countries and different healthy and clinical population. Its construct validity was controlled by genetic markers as well (reviewed by Feder et al., Davidson, Connor [21,22]). The CD-RISC is an eligible self-report method to reveal the putative neurobiological markers that associate with the resilience traits.

\section{Genetic studies with CD-RISC}

The interactions between individuals' genetic dispositions and their life history and environmental conditions determine the degree of the adaptation or maladaptation to adverse events, coping capacities, personality traits, and stress responses. Comprehensive studies have in part revealed the psychobiological and molecular genetics roots of the resilience [21,23-25] but the contradictory results showed that the pattern and the nature of the associations is still incomplete. The trans-diagnostic data revealed some of the biological markers of resilience that may be accounted as a preventive factor for mental diseases and supports the recovery from mental or somatic illness [26]. Studies for bio-psychological associations and mechanism for resilience covers most of the areas of cognitive neuroscience. Most of the study focuses on the examination of the dopaminergic, serotonergic systems and the hypothalamic-pituitary-adrenal (HPA) axis that may playes an essential role in the genetic bases of psychological resilience $[27,28]$.

The resilience traits associate with the norepinephrine transporter mechanism that engages with the stabilization of cardiovascular function in mental disorder and reduces the responsibility to aversive situations $[14,23]$. Further, psychophysiological reactivity examinations showed that highly resilient individuals' cardiovascular reactivity is moderated, and the recovery to the cardiovascular baseline is faster after stress exposure than in subject with low CD-RISC scores [29]. The perceptual expectancy bias towards positive events in person with high scores in CD-RISC is higher [30,31], that may be related to the dopamine transmissions. The dopamine receptor DRD4-VNTR polymorphism 7-repeat allele associated with higher CD-RISC score and has an advantageous effect in response to reward and associated with dispositional optimism, positive emotions providing the larger cognitive capacity to reappraisal for the contextual cues of aversive conditions [32]. On the other hand, the serotonin system closely related to mood regulation and modulates the emotional response to stress in fear and anxiety-provoking situations, but its association with CD-RISC scores is debated. Low resilience score related to with 5 HTTLPR short allele [33], however, in another study has found a reverted relationship [34]. Further, the important nerve growth factor, brain-derived neurotrophic factor (BDNF) influences on the neuronal development and take a part in the brain plasticity that may be a next general biological mechanism in the evolution of the resilience [21].

\section{Relationship of resilience to adaptive and mal- adaptive personality traits}

The theoretical starting point of this study originated from the finding from recent studies suggest that most of the mental disease can be interpreted in the frame of the diathesis vulnerability and stress model [35] where the vulnerability is manifested in maladaptive biological functioning, genetic influence on the intensity and frequency of dysfunctional behavior, cognition, and perceptual disorders and the development of the maladaptive patterns of personality traits. One of the most serious mental maladaptation spectrum is schizophrenia spectrum disorders that elicit different rate cognitive, behavioral and affective difficulties in a spectrum ranged from normal functioning to psychosis. Considering the multilevel and trans-diagnostic nature of the genotype and psychological phenotype associations the resilience was accounted as an endophenotype for a behavioral, cognitive and emotional regulation mechanism that has an essential part in the healthy adaptation to environmental requirement. Consequently, resilience-related genetic characteristics beside other self-regulation functions (e.g. self-esteem, cognitive reappraisal) may be an agent to inhibit the manifestation for symptoms of the schizophrenia spectrum disorder, first of all in 
the degree for the schizotypy $[36,37]$. The successful coping with and adaptation the threatening of personal integration for aversive situations associated with the genetically based psychological mechanism. The genetically based pathways that mediate resilient phenotypes controls a range of socially constructed functions and social rules, interpretations, a drive to regulate the self-function, controls of the personal experiences and the phenotype of biological reactions. Considering that vulnerable functions attend in a premorbid personality structure, such us in schizotypy, healthy individual were studied to find an association between adaptive (resilience) and maladaptive (schizotypy) traits with different relevant genotypes. In this study the main biological determined features of the resilience, the recovery from chronic stress with positive developmental outcomes and the positive emotions based tenacity in the execution of a set of goals for a longer life period of time to be the object of the analysis for genetic background mechanism of resilience. The resilience an adaptive and heritable trait with a relatively small genetical contribution and manifests both in the adequate behavior organization, coping capabilities [38] mature cognitive and interpersonal functioning and is negatively associated with maladaptive traits such as schizotypy and the anxiousness $[39,40]$. Measuring the adaptive and maladaptive traits, listed above, may be beneficial for the identification of additional genetic components for resilience.

\section{Hypothesis}

The object of this study is to examine bio-psychological associations with adaptive (resilience and self-esteem) and maladaptive (anxiousness and schizotypy) personality traits. These traits depending on their rates are considered as a genetically based predisposition for a mental deficiency or resilient behavior. To assess the advantageous or disadvantageous effect of genetic polymorphisms different single nucleotide polymorphisms SNPs were used. The SNPs selection based on the hypothesis mentioned above, that resilience serves as a preventive factor avoiding several psychopathology and psychiatry disorders. Two adaptive, resilience and self-esteem, and two maladaptive traits, anxiety sensitivity, and the schizophrenia spectrum-related schizotypy were assessed to analyzed differences between the selected of SNPs. The selection based on trans-diagnostic SNPs that associate with different maladaptive behavior, and mental disorder involving, autism, ADHD, schizophrenia, major depression, and anxiety. The literature of the association study on healthy functioning and mental disorder is expanded and most of the cases debated $[21,28,41]$. The genome-wide association studies (GWAS) focus on the defined disease categories but the etiology of the assessed disease and the predisposing personality functioning in most of the case remained in the shade. The resilience as a personal adaptation strategy contains exactly defined cognitive and emotional regulation functions for cope physical and mental diffi- culties that manifest, but in a different rate, in the different pole of the adaptive and maladaptive dimension. In the present study the resilience going to be presented with all functional aspects (tenacity, self-regulation under stress, quick physical and mental recovery from adverse events, sense of being supported, and drive to construct causal meaning of actions, feeling and social and physical environment), and further the self-esteem to be accounted as a principal aspect of the adaptation success. We suppose that trans-diagnostic maladaptive anxiety sensitivity and the schizotypy traits and the adaptive resilience and self-esteem related SNPs association need to be different. In this study some of the maladaptive and adaptive psychological traits to be associated with the selected SNPs to reveal the resilience related genes that may be advantageous in the personality development in healthy resilient persons.

\section{SNPs selection method}

The method of the SNPs selection based on the literature of the genetic association studies for maladaptive traits that may be accounted as biological predispositions in schizophrenia spectrum disorders, mood, and anxiety disorders as well. These genetic effects are present in the normal population as well, but the adaptive personality traits moderates the phenotypes of this genetic vulnerability [28]. Similar trait constitutions influence the manifestation of uncommon behavior variants and play a role in the development of the creativity, artlike view and the realization of unfamiliar but original performances. The study during SNPs selections focused on a set of maladaptive transdiagnostic genes that associates with a schizophrenia spectrum disorder, anxiety, drug dependences, and depression. Based on the adequate literature [42-48] for the association analysis in the mentioned maladaptive psychiatry disorders related set of SNPs were composed for test of the hypothesis of this study. Considering the different contribution in regulation of affective and cognitive functions a various set of the serotoninergic and dopaminergic system related genotypes DRD2 (rs6277, rs1076560), RGS4 (rs2661319), COMPT (rs4680), HTR1B (rs13212041), further NRG1 (rs10503920), DTNBP1 (rs760761), andMIR137 (rs2660304) were the object of the genotype and endophenotype traits association study.

\section{Materials and Methods}

\section{Participants}

Participants included 347 Caucasian graduate and postgraduate students (women $=197 ; 71.3 \%$, mean age $=21.32$ years, $\mathrm{SD}=1.6 ;$ men $=149 ; 28.7 \%$, mean age $=$ 21.68 years, $S D=2.1 ;$ min- $\max =18-31$ ) there were enrolled in the study from three different Hungarian faculties (University of Pécs). All persons participated voluntarily and at no cost for the examinations. The study was conducted in accordance with the Helsinki Declaration (ethical allowance No. 6732 PTE/2017). 


\section{Procedure}

The participants had differed in degree of resilience trait. Moreover, maladaptive personality traits also were assessed by a self-reported questionnaire. The DNS sample taking and the administration of questionnaires was carried out on the same session.

\section{Measures}

Genotyping: Genotype analysis of the selected single nucleotide polymorphisms was carried out by an innovative, high-throughput technique called OpenArray ${ }^{\circledR}$. This method is based on the application of allele-specific TaqMan probes labeled with different fluorescent dyes (FAM or VIC), respectively, in a real-time PCR reaction. During amplification, the signal of FAM or VIC or both increase, corresponding to the two homozygous and the heterozygote genotype, respectively. Reactions are carried out on the surface of the OpenArray ${ }^{\circledR}$ slides in $\mathrm{nl}$-scale reactions offering extremely low reagent consumption and high throughput. Each OpenArray ${ }^{\circledR}$ slide is a low-density array divided to 48 sub arrays; each sub array consists of 64 through holes allowing the determination of more than 3000 genotypes simultaneously in a single real-time PCR.

Genomic DNA samples were isolated from buccal samples by salting out the proteins, which was followed by the precipitation of DNA by isopropanol and ethanol using standard procedures. Samples were diluted to the range of $20-50 \mathrm{ng} / \mu \mathrm{L} .2 .5 \mu \mathrm{l}$ of them were mixed with 2.5 $\mu \mathrm{L}$ TaqMan $^{\mathrm{TM}}$ OpenArray ${ }^{\mathrm{TM}}$ Genotyping PCR Master Mix containing the AmpliTaq Gold ${ }^{\circledR}$ DNA-polymerase, deoxyribonucleoside-triphosphates (building blocks of the generated DNA) and an optimized buffer. This mixture was loaded by the AccuFill ${ }^{\mathrm{TM}}$ System on the TaqMan ${ }^{\mathrm{TM}}$ OpenArray $^{\mathrm{TM}}$ Genotyping Plates, which contained the primers and the TaqMan ${ }^{\circledR}$ probes imposed on the edge of the through-holes. PCR, detection of the fluorescent signals during PCR as well as analysis of the clusters and calling of the genotypes were carried out by the QuantStudio $^{\text {TM }}$ 12K Flex Real-Time PCR platform. Call rate was higher than $91 \%$ in the case of each analyzed locus. Positive and negative controls were employed to verify the reliability of the system: duplicate samples (positive controls) on the same as well as on different slides resulted in concordant genotypes in each case, as well as no amplification could be detected in the non-template (negative) controls.

\section{Traits measurement}

Connor-Davidson Resilience Scale (CD-RISC-25, Connor, Davidson, 2003 [17]) Hungarian adaptation [49]. The scale contains 25 items. The scoring is based on summing the total of all item, each of them is scored from 0-4. Factor analytic studies revealed five facets of the scale. The first captured aspect is the tenacity with a strong sense of self-efficacy. The second involves capabilities to keep emotional and cognitive control under pressure. The third refers to physical and mental adaptation in a chronic stress situation and fast recovery from it. Forth, Belief in the availability of social support. Fifth, believe in the causality and the meaningful life [17]. Moreover, the higher scores reflect greater resilience which indicates an elevated tenacity, a quick adaptation to the adverse situation. Moreover, that may be expressing an ability to find meaning from both positive and negative life events and control behavior under stress. From the interpersonal point of view, resilience contains elevated self-esteem, goal-directedness, and stability in somatic and mental state and matured coping pattern. The lower scores were found in psychiatric patients with social maladjustment and persons having difficulty coping with stress [50]. In the present sample, the cumulative $\%$ values $=59.1$; the total scale internal consistency was $\alpha=0.91$. Cronbach's $\alpha$ for the factors were $=(1) 0.91$; (2) 0.87 ; (3) 0.67 ; (4) 0.61 ; (5) 0.60 .

Rosenberg Self-esteem Scale, RSES, [51,52] is a unidimensional model to measure for adaptive self function consisting self-confidence and self-depreciation traits. The RSES consists of 10 items, the response scale ranged between strongly agree (4) and strongly disagree (1) scale with any reverse-scored items. Higher scores indicate higher self-esteem and associates with better interpersonal adaptation, emotional wellbeing, optimism, and healthier lifestyle [53] and the individual with self-esteem have higher score mature self-regulation and adequate coping with stress $[54,55]$.

Anxiety Sensitivity Index [56,57] contains 16 items. The scoring ranges from 0 to 4 . Clinical and nonclinical studies have shown that the ASI-R has good psychometric features distinguishing patients and healthy control groups. The ASI-R was constructed as a unidimensional scale with three correlated factors: Physical concern, social concerns, and cognitive concerns [58]. The total score of ASI-R indicates an elevated vulnerability to several types of anxiety disorders [59]. Since the internal consistencies of these factors are debated in this way the unidimensional utilization is accepted [59]. In this sample, Cronbach's alpha for the total score of ASI-R is 0.89 .

Schizotypal Personality Questionnaire-Brief Revisited (SPQ-BR) [60-62] contains 32 items with five rates Liker scale scoring from 0 to 4 for measure schizotypal personality traits that serve as an additional tool for DSM-5 to define schizophrenia spectrum disorder. High schizotypy individuals showed elevated risk to produce schizophrenia-like symptoms. The three first-order factors contain cognitive, interpersonal and disorganized symptoms. The cognitive factor involves suspiciousness, referential thinking, and magical thinking, unusual perceptual experience symptoms that similar to positive symptoms in schizophrenia. The interpersonal factor refers to social anxiety, loneliness, and constricted affect symptoms that similar to the negative symptom in 
Table 1: The total scores of the examined personality traits.

\begin{tabular}{|c|c|c|c|}
\hline & $\mathrm{N}$ & \multirow[t]{3}{*}{ Mean (SD) } & \multirow[t]{3}{*}{$\mathrm{t}$ - value } \\
\hline & male & & \\
\hline & female & & \\
\hline \multirow[t]{2}{*}{ CD-RISC Total score for resilience } & 131 & $68.94(13.4)$ & \multirow[t]{2}{*}{$\mathrm{t}=0.42$ n.s. } \\
\hline & 167 & 69.95 (13.3) & \\
\hline \multirow[t]{2}{*}{ RSES Rosenberg Self-esteem } & 147 & $30.21(6.3)$ & \multirow[t]{2}{*}{$\mathrm{t}=1.28 \mathrm{n} . \mathrm{s}$} \\
\hline & 196 & $29.34(6.1)$ & \\
\hline \multirow[t]{2}{*}{ ASI Anxiousness } & 144 & $15.43(9.7)$ & \multirow[t]{2}{*}{$\mathrm{T}=0.26$ n.s. } \\
\hline & 195 & $15.41(9.3)$ & \\
\hline SPQ-BR Schizotypy & 145 & $40.37(17.6)$ & $\mathrm{T}=0.59$ n.s. \\
\hline
\end{tabular}

Table 2: Correlation matrix for adaptive and maladaptive traits controlled by gender. 1) CD-RISC Tenacity, self-efficacy; 2) CDRISC Control under stress; 3) CD-RISC Adaptation and quick recovery; 4) CD-RISC Social support availability; 5) CD-RISC Meaningful life, and causality; 6) CD-RISC Total score for resilience; 7) RSES Rosenberg Self-esteem Scale Total score; 8) Anxiety Sensitivity Index, Anxiousness; 9) Schizotypy Personality Questionnaire SPQ-BR Schizotypy Total score.

\begin{tabular}{|c|c|c|c|c|c|c|c|c|c|}
\hline Variables & 1 & 2 & 3 & 4 & 5 & 6 & 7 & 8 & 9 \\
\hline 1. CD-RISC Tenacity & - & $0.698^{* *}$ & $0.496^{* *}$ & $0.357^{* *}$ & $0.140^{*}$ & $0.889^{* *}$ & $0.462^{* *}$ & $-0.152^{*}$ & $-0.257^{* *}$ \\
\hline 2. CD-RISC Control & & - & $0.547^{* *}$ & $0.371^{* *}$ & 0.054 & $0.873^{* *}$ & $.497^{* *}$ & $-0.232^{* *}$ & $-0.374^{* *}$ \\
\hline 3. CD-RISC Adaptation & & & - & $0.350^{* *}$ & $0.170^{* *}$ & $0.706^{* *}$ & $0.303^{* *}$ & -0.053 & $-0.152^{*}$ \\
\hline 4. CD-RISC Support & & & & - & $0.224^{* *}$ & $0.535^{\star *}$ & $0.379^{* *}$ & $-0.130^{\star}$ & $-0.352^{* *}$ \\
\hline 5. CD-RISC Meaningful & & & & & - & $0.308^{* *}$ & 0.117 & 0.0094 & -0.038 \\
\hline 6. CD-RISC Total score & & & & & & - & $0.529^{* *}$ & $-0.173^{* *}$ & $-0.331^{* *}$ \\
\hline 7. RSES Total score & & & & & & & - & $-0.302^{* *}$ & $-0.443^{* *}$ \\
\hline 8. ASI Anxiousness & & & & & & & & - & $0.586^{\star *}$ \\
\hline 9. SPQ-BR Schizotypy & & & & & & & & & - \\
\hline Schizotypy & & & & & & & & & \\
\hline
\end{tabular}

$P<0.05^{*} ; p<0.01^{* *}$

schizophrenia. Disorganized behavior factor involves odd speaking and excessive behavior symptoms. An individual with high summarized factors scores is vulnerable to schizophrenia spectrum disorders that are one of the chronic mental disorders that cause an essential maladaptation to the everyday challenges. The SPQ-BR has strong internal consistency and validity. In the present sample, the Cronbach alpha was 0.92 .

\section{Results}

\section{Descriptive statistics and sex differences of the sam- ple}

The examined total scores of the CD-RISC, RSES, ASI and SPQ-BR personality questionnaires have not indicated sex differences (Table 1).

\section{Correlation analysis of the adaptive and maladap- tive personality traits scores}

The association analysis showed an opposite relationship between adaptive resilience, self-esteem and maladaptive anxiety and schizotypal traits. However, this reverted relation is not significant in the case of the CD-RISC Meaningful life and causality factor. The adaptive recovery from chronic stress and anxiousness has not shown a significant relationship (Table 2).
The differences between the hetero- and homozygoteous genotypes in the adaptive (CD-RISC, RSES) and maladaptive traits (ASI and SPQ-BR) for the examined SNPs

In the case of RGS4 (rs2661319) F (df. 2-284, CD$R I S C)=1.73$, ns., $F(2-321$, RSES $)=0.53$ ns., $F(2-318$, ASI $)$ $=1.62$ ns., $F(2-313$, SPQ_BR) $=0.04$ ns.; DRD2 (rs6277) $F(2-298$, CD-RISC $)=0.27$, ns., $F(2-338$, RSES $)=0.35$ ns., $F(2-335, A S I)=0.68$ ns., $F\left(2-330, S P Q \_B R\right)=0.01$ ns.; DTNDP1 (rs760761) F (df. 2-293, CD-RISC) $=0.46$, ns., $F(2-332, R S E S)=2.03$ ns., $F(2-3298, A S I)=1.06$ ns., $F$ $(2-325$, SPQ_BR) $=0.77$ ns.; HTR1B $(r s 1321204) \mathrm{F}$ (df. $2-286$, CD-RISC) $=0.41$, ns., $F(2-324$, RSES $)=0.97$ ns., $F(2-321, A S I)=3.41$ ns., $F\left(2-316, S P Q \_B R\right)=1.01$ ns.; DRD2 (rs1076560) F (df. 2-297, CD-RISC) $=0.10$, ns., $F$ $(2-335$, RSES $)=0.19$ ns., $F(2-332, A S I)=0.68$ ns., $F(2-$ 327, SPQ_BR) $=0.83$ ns.; COMT (rs4680) F (df. 2-298, $C D-R I S C)=1.40$, ns., $F(2-338$, RSES $)=1.92$ ns., $F(2-335$, ASI $)=0.45$ ns., $F(2-330$, SPQ_BR $)=0.40$ ns.; MIR137 (rs2660304) F (df. 2-297, CD-RISC) $=1.29$, ns., F (2-337, RSES $)=1.68$ ns., $F(2-334, A S I)=1.06$ ns., $F(2-329$, SPQ $\mathrm{BR})=0.78$ ns.; NRG1 (rs10503920) F (df. 2-289, CD-RISC) $=6.94, p<0.001 ., \mathrm{F}(2-329, \mathrm{RSES})=4.32, p<0.014 ., \mathrm{F}$ $(2-326, A S I)=1.31$ ns., $F\left(2-321, S P Q \_B R\right)=0.41$ ns. 
Table 3: Adaptive and maladaptive personal characteristics of participants with different neuroregulin 1 (rs10503920) genotypes. Bonferroni post hoc test was used to determine the differences in the three genotypes.

\begin{tabular}{|c|c|c|c|c|c|}
\hline $\begin{array}{l}\text { SNP rs } 10503920 \text { genotype } \\
\text { frequency } \\
\text { (1) GG, } 11.4 \% \text {, (2) AA, } 47 \% \text {, (3) } \\
\text { AG, } 41.6 \%\end{array}$ & $\begin{array}{l}\text { hetero and } \\
\text { homonozygote } \\
\text { bases pairs }\end{array}$ & $\mathrm{N}$ & Mean SD & $\mathrm{F}$ & Significances $p=$ \\
\hline \multicolumn{6}{|l|}{ ADAPTIVE TRAITS } \\
\hline \multirow[t]{3}{*}{ CD-RISC Tenacity, self-efficacy } & GG & 33 & $24.4(7.8)$ & \multirow[t]{3}{*}{5.12} & \multirow[t]{3}{*}{$0.005,1-3$} \\
\hline & AA & 136 & $26.6(5.7)$ & & \\
\hline & $A G$ & 121 & $27.92(5.0)$ & & \\
\hline \multirow[t]{3}{*}{ CD-RISC Control under stress } & GG & 33 & $19.6(6.1)$ & \multirow[t]{3}{*}{5.57} & \multirow[t]{3}{*}{$0.002,1-3$} \\
\hline & AA & 136 & $21.2(5.3)$ & & \\
\hline & $A G$ & 122 & $22.8(4.9)$ & & \\
\hline \multirow{3}{*}{$\begin{array}{l}\text { CD-RISC Adaptation and quick } \\
\text { recovery under stress }\end{array}$} & GG & 33 & $9.2(3.1)$ & \multirow[t]{3}{*}{4.71} & \multirow{3}{*}{$\begin{array}{l}0.008,1-2 \\
1-3\end{array}$} \\
\hline & AA & 136 & $10.4(2.5)$ & & \\
\hline & AG & 123 & $10.7(2.5)$ & & \\
\hline \multirow{3}{*}{$\begin{array}{l}\text { CD-RISC Social support } \\
\text { availability }\end{array}$} & GG & 33 & $6.1(1.8)$ & \multirow[t]{3}{*}{1.02} & \multirow[t]{3}{*}{0.36} \\
\hline & AA & 136 & $6.2(1.8)$ & & \\
\hline & $A G$ & 124 & $6.4(1.6)$ & & \\
\hline \multirow{3}{*}{$\begin{array}{l}\text { CD-RISC Meaningful life, and } \\
\text { causality }\end{array}$} & GG & 33 & $4.6(2.3)$ & \multirow[t]{3}{*}{0.99} & \multirow[t]{3}{*}{0.99} \\
\hline & $\mathrm{AA}$ & 136 & $4.6(2.2)$ & & \\
\hline & $A G$ & 124 & $4.5(2.3)$ & & \\
\hline \multirow[t]{3}{*}{ CD-RISC Total score for resilience } & GG & 33 & $63.9(17.4)$ & \multirow[t]{3}{*}{6.39} & \multirow[t]{3}{*}{$0.001,1-3$} \\
\hline & AA & 136 & $69.1(12.2)$ & & \\
\hline & $A G$ & 120 & $72.7(11.7)$ & & \\
\hline \multirow[t]{3}{*}{ RSES Self-esteem Scale } & GG & 38 & $29.9(6.8)$ & \multirow[t]{3}{*}{4.32} & \multirow[t]{3}{*}{$0.0142-3$} \\
\hline & AA & 150 & $28.7(6.1)$ & & \\
\hline & $A G$ & 144 & $30.8(6.1)$ & & \\
\hline \multicolumn{6}{|l|}{ MALADAPTIVE TRAITS } \\
\hline \multirow[t]{3}{*}{ ASI Anxiousness } & GG & 38 & $16.6(9.9)$ & \multirow[t]{3}{*}{1.39} & \multirow[t]{3}{*}{0.25} \\
\hline & AA & 150 & $16.1(10.1)$ & & \\
\hline & AG & 141 & $14.5(8.9)$ & & \\
\hline \multirow[t]{3}{*}{ SPQ-BR Schizotypy } & GG & 34 & $39.08(17.8)$ & \multirow[t]{3}{*}{0.38} & \multirow[t]{3}{*}{0.68} \\
\hline & AA & 151 & $40.67(17.7)$ & & \\
\hline & $A G$ & 139 & $38.95(17.1)$ & & \\
\hline
\end{tabular}

The One-way ANOVA analysis revealed that the examined degree of the adaptive traits, the resilience and self-esteem scores differ in the NRG1 gene's rs10503920 polymorphism. However, other tested SNPs have not shown relations with the examined adaptive and maladaptive traits. In the next step, the rs10503920 NSP has considered as an object for a detailed post hoc multiple comparisons with an enlargement of the factorial variables of the resilience (Table 3 ). The analysis revealed that AG heterozygoteous genotype of the rs 10503920 indicated higher resilience score comparing with GG homozygoteous genotype. This higher score composed from different features of resilience involving tenacity, retaining of control under stress, and quick somatic a psychological recovery after chronic adverse situations. In case of AA homozygoteous genotype in the fast recovery factor emphasized that the A genotype is a re- markable determination in the emergence of resilience, while the GG homozygoteous genotype can be accounted as a maladaptive variant in point of view of behavioral regulation and role in a trans-diagnostic vulnerability for mental deficiency. But it has to underline the two adaptive traits behave differently in its relations to the NRG1 SNP. Since higher resilience and self-esteem score related to $A G$ heterozygoteous genotype but lower resilience score detected in the case of GG while in self-esteem lower score related to AA genotype. Consequently, the AG genotype linked to elevated adaptation capability while the $A A$ and $G G$ are a disadvantage but in different reason. The origin of this contradictory patter has until no explored, but it may be suggested that tenacity and higher physiological and psychological recovery from the aversive situation may be the main components that make a basic difference between self-esteem and 
resilience. The rs10502039 SNP in this healthy highly educated sample cannot be indicated essential differences between polymorphism in maladaptive anxiousness and schizotypy.

\section{Discussion}

The presented study revealed that NRG1 gene's rs10503920 polymorphisms A/G genotype is related to the degree of resilience. Individuals with $A / G$ have stronger resilience than those with the $G / G$ genotype. Similar relation has been found in persons with the adaptive self-esteem trait score where the individuals with the presence of $A / G$ have higher self-esteem compared with A/A genotype. In the case of maladaptive traits (schizotypy and anxiousness), similar patterns have not been detected. Other examed SNPs relations with adaptive and maladaptive traits have not been found. In a second step, the resilience sub-factors vs. SNP rs10503920 comparison were the object of the examination and found that except with social support availability and meaningful life and causality searching, all of the resilience sub-factors have higher score in the presence of $A / G$ polymorphism in NRG1 gene comparing $G / G$ and in adaptation and faster recovery under stress in $A / A$.

Considering the present knowledge the resilience is associated with different domains of the brain structure that engages with cortico-limbic inhibition functions and cognitive and affective processes and control under stress [31]. Further, the psychophysiological adaption to the stress and recovery for the healthy functioning associated with the stability of the parson psychophysiological system containing the cardiovascular stability for a shorter phasic and longer tonics stress situations. The successful adaptation to the adversities is determined by coping, tenacity, the social buffering capability of the persons and the adequate cognitive and affective regulation and integration with the biological reaction to stress [63]. The constructing social support and seeking support from others, if it is needed, are an essential outcome factor of the resilience [7]. The correlation analyses of our presented data supported that social support is a major agent in the total score of resilience. However, fine gradient analysis with resilience components and the rs10503920 SNP has not indicated difference between the low and high scores on the CR-RISC social support and meaningful life scales. These mentioned scales closely related to the social and environmental context of resilience. Taking together, the NRG1 gene's rs10503920 polymorphism related to the tenacity, control under stress, and faster recovery under stress resilience factors, but the similar association in the social support and meaning searching factor cannot be detected. Therefore, the NRG1 gene rs10503920 polymorphism is advantageous in the evolution of the resilience endophenotype first of all where the tenacity, the goal-directed behavior, the cognitive and affective control functions have kept under stress. Further, the self-control and faster mental and physical recovery to the successful growth trajectory is the main stable components in the resilience traits pattern. Therefore, these sub-factors refer to the cognitive bio-psychological stability to control the environmental challenges and basically involved in the maintenance of the successful executive functions. Consequently, it may be suggested that the NRG1 related rs 10503920 polymorphism accounted as a candidate genetic marker for the successful executive control that manifests in a high score on CR-RISC resilience and in self-esteem scales. However, the other components related to the environmental and social support effect to hold up or the seeking of social support it should be explored in another gene loci.

Neuregulins are important growth factors that being engaged with cardiac development. The fragments of neuregulins have been found to be cardio-protective response under to stress and plays a role in cardiac homeostasis, angiogenesis [64,65], oncological $[66,67]$ and psychiatrical disorders and other organs' development and functional stability or instability $[68,69]$. Our findings support the suggestion that NRG1 rs10503920 genetic variation is one of the essential components of the adaptive behavior related to psychological resilience. Considering the trait pattern analysis of resilience it may be stated the role of rs10503920 SNP manifested in the stability of the cognitive and affective functions integration and the keeping of the executive functioning under stress. However, the presented data showed the rs10503920 SNP has no association with the prevention for the risk for anxiousness and schizotypy. Studies with rs10503920 A/G polymorphisms found an association with psychiatric disorders (e.g. schizophrenia and bipolar disorder, autisms) and the human organs optimal neuro-development in GABA receptors and first of all in deficits in auditory information processing $[43,70]$. This NRG1 polymorphism has been demonstrated to affect brain structure with decreased grey matter volume and white matter density and integrity $[45,71]$ in several brain regions and increased volume of lateral ventricles in schizophrenia [72].

In sum, this study focused on the analysis between a group of mental adaptation-related genotypes and a psychological phenotype of the resilience. The results revealed that The NRG1 gene's rs10503920 polymorphism is advantageous in the evolution of the resilience endophenotype, where the tenacity, the goal-directed behavior, the maintained cognitive and affective self-control under stress and faster mental and physical recovery to the successful growth trajectory are the main stable components in the resilience traits pattern.

\section{Limitations}

The assessed sample comes from a middle-class family cohort with excellent intellectual capacity. They're all university student in medical and engineering faculties. The previous and actual life-threatening events have 
not been monitored. The results refer only to a Caucasian university student sample wherein the trait ego-resilience was assessed by a self-reported scale. However, the used CD-RISC method is a prominent valid and reliable tools to measure resilience in lots of cultures and in healthy and patient groups.

\section{Acknowledgments}

The study was supported by the National Research, Development and Innovation Office (K- 120334. KJ), by ÚNKP-3-IV-PTE-96 New National Excellence Program of the Ministry of Human Capacities.

\section{Author Contributions Statement}

Theoretical considerations KJ, RZS, RJ, EZS, text editing $\mathrm{KJ}, \mathrm{EZS}, \mathrm{KE}$, statistical analysis $\mathrm{TI}, \mathrm{HU}$, data gathering $\mathrm{TI}, \mathrm{ML}, \mathrm{EZS}$.

\section{Conflict of Interest Statement}

There is no conflict of interest in the case of the authors of the article.

\section{References}

1. Luthar SS (2006) Resilience in Development: A Synthesis of Research across Five Decades. In: D. Cicchetti, DJ Cohen ( $2^{\text {nd }}$ edn), Developmental Psychopathology: Risk, Disorder, and Adaptation. Wiley Online Library, New York, 739-795.

2. Schwager S, Rothermund K (2014) The automatic basis of resilience: Adaptive regulation of affect and cognition. In: M Kent, MC Davis, JW Reich (edn), The resilience handbook: Approach to stress and trauma ,Routledge/Taylor and Francis Group, New York, 55-72.

3. Werner EE, Smith RS (2001) Journeys from childhood to midlife: Risk, resilience, and recovery. Cornell University Press, Ithaca, New York.

4. Marmot MG, Fuhrer R (2004) Socioeconomic position and health across midlife. In: OG Brim, CD Ryff, RC Kessler (Edn), Studies on successful midlife development .How healthy are we?: A national study of wellbeing at mid-life. University of Chicago Press, Chicago, 64-89.

5. Werner EE (1995) Resilience in development. Curr Dir in Psychol Sci 4: 81-85.

6. Carle AC, Chassin L (2004) Resilience in a community sample of children of alcoholics: Its prevalence and relation to internalizing symptomatology and positive affect. J App Deve Psychol 25: 577-595.

7. Ozbay F, Charney D, Southwick S (2008) Social support and resilience to stress across the life span: A neurobiological framework. Curr Psychiatry Rep 10: 304-310.

8. Oshio A, Taku K, Hirano M, Saeed G (2018) Resilience and Big Five personality traits: A meta-analysis Pers Individ 127: 54-60.

9. Alves ND, Correia JS, Patricio P, Mateus-Pinheiro A, Machado-Santos AR, et al. (2017) Adult hippocampal neuroplasticity triggers susceptibility recurrent depression. Transl Psychiatry 7: e1058.

10. Masten AS, Best KM, Garmezy N (1990) Resilience and Development: Contributions from the Study of Children Who Overcome Adversity. Dev Psychopathol 2: 425-444.

11. Caffo E, Belaise C (2003) Psychological aspects of trau- matic injury in children and adolescents. Child Adolesc Psychiatr Clin N Am 12: 493-535.

12. Norris FH, Stevens SP, Pfefferbaum B, Wyche KF, Pfefferbaum RL (2008) Community resilience as a metaphor, theory, set of capacities, and strategy for disaster readiness. Am J Community Psychol 41: 127-150.

13. Tannenbaum B, Anisman H (2003) Impact of chronic intermittent challenges in stressor-susceptible and resilient strains of mice. Biological Psychiatry 53: 292-303.

14. Charney DS (2004) Psychobiological mechanisms of resilience and vulnerability: Implications for adaptation to extreme stress. Am J Psychiatry 161: 195-216.

15. Campbell-Sills L, Cohan SL, Stein MB (2006) Relationship of resilience to personality, coping, and psychiatric symptoms in young adults. Behav Res Ther 44: 585-599.

16. Haskett E, Nears K, Ward S, McPherson AV (2006) Diversity in the adjustment of maltreated children: Factors associated with resilient functioning. Clin Psychol Rev 26: 796-812.

17. Connor KM, Davidson JRT (2003) Development of a new resilience scale: The Connor-Davidson Resilience Scale (CD-RISC). Depress Anxiety 18: 71-82.

18. Luthar SS, Cicchetti D, Becker B (2000) The construct of resilience: A clinical evaluation and guidelines for future work. Child Dev 71: 543-562.

19. Tedeschi RG, Calhoun LG (1996) Posttraumatic growth inventory: Measuring the positive legacy of trauma. J Trauma Stress 9: 455-471.

20. Pangallo A, Zibraras L, Lewis R, Flaxman P (2015) Resilience through the lens of interactionism: A systematic review. Psychol Assess 27: 1-20.

21. Feder A, Nestler EJ, Charney DS (2009) Psychobiology and moleculargenetics of resilience. Nat Rev Neurosci 10: 446-457.

22. Davidson JRT, Connor KM (2017) Connor-Davidson Resilience Scale (CD-RISC) Manual.

23. Davidson JRT, Watkins L, Owens M, Stan Krulewicz, Kathryn Connor, et al. (2005) Effects of Paroxetine and Venlafaxine XR on Heart Rate Variability in Depression. J Clin Psychopharmacol 25: 480-484.

24. Cicchetti D, Blender JA (2006) A multiple-level of analysis perspective on resilience: Implications for the developing brain, neural plasticity, and preventive interventions. Ann NY Acad Sci 1094: 248-258.

25. Niitsu K, Rice MJ, Houfek JF, Scott F Stoltenberg, Kevin A Kupzyk, et al. (2018) A systematic review of genetic influence on psychological resilience. Biol Res Nurs 21: 61-71.

26. Brunetti M, Marzetti L, Sepede G, Filippo Zappasodi, Vittorio Pizzella, et al. (2017) Resilience and cross-network connectivity: A neural model for post-trauma survivals. Progression in Neuropsychopharmacology and Biological Psychiatry $77: 110-119$.

27. Vythilingam M, Nelson EE, Scaramozza M, Tracy Waldeck, Gary Hazlett, et al. (2009) Reward circuitry in resilience to serve trauma: An fMRI investigation of resilient special-forces soldiers. Psychiatry Res 172: 75-77.

28. Wu G, Feder A, Cohen H, Joanna J Kim, Solara Calderon, et al. (2013) Understanding resilience. Front Behav Neurosci 7: 10 .

29. Lü W, Wang Z, You X (2016) Physiological responses to repeated stress in individuals with high and low trait resilience. Biological Psychology 120: 46-52. 
30. Arce A, Simmons AN, Stein, Piotr Winkielman, Carla Hitchcock, et al. (2009) Association between individual differences in self-reported emotional resilience and the affective perception of neutral faces. Journal of Affective Disorders 114: 286-293.

31. Gupta A, Love A, Kilpatrick L, Jennifer S Labus, Ravi Bhatt, et al. (2017) Morphological brain measures of cortico-limbic inhibition related to resilience. J Neurosci Res 95: 17601775.

32. Das D, Cherbuin N, Tan X, Kaarin J Anstey, Simon Easteal (2011) DRD4-exonIII-VNTR moderates the effect of childhood adversities on emotional resilience in young-adults. PLoS One 6: 201-277.

33. Stein M, Campbell-Sills L, Gelernter J (2009) Genetic variation in 5HTTLPR is associated with emotional resilience. Am J Med Genet B Neuropsychiatr Genet 150: 900-906.

34. O'Hara R, Marcus P, Thompson WK, John Flournoy, Ipsit Vahia, et al. (2012) 5HTTLPR short allele, resilience and successful aging in older adults. Am J Geriatr Psychiatry 20: 452-456.

35. Meehl PE (1962) Schizotaxia, schizotypy, schizophrenia. American Psychologist 17: 827-838.

36. Troy A, Mauss I (2011) Resilience in the face of stress: Emotion regulation as a protective factor. In: S Southwick, B Litz, D Charney, M Friedman, Resilience and Mental Health: Challenges Across the Lifespan. ( $4^{\text {th }}$ edn), Cambridge University Press, UK, 30-44.

37. Debbané M, Barrantes-Vidal N (2015) Schizotypy from adevelopmental perspective. Schizophr Bull 41: S386-395.

38. Navrady LB, Zeng Y, Clarke TK, Mark J Adams, David M Howard, et al. (2018) Genetic and environmental contributions to psychological resilience and coping. Wellcome Open Res 3: 12.

39. Hjemdal O, Vogel PA, Solem S, Kristen Hagen, Tore C Stiles (2011) The relationship between resilience and levels of anxiety, depression, and obsessive-compulsive symptoms in adolescents Clin Psychol Psychother 18: 314-321.

40. Barahmand U, Ahmad RHS (2016) Psychotic-like experiences and psychological distress: the roleof resilience. $J$ Am Psychiat Nurses Assoc 22: 312-319.

41. Liu H, Zhang C, Ji Y, Yang L (2018) Biological and psychological perspective of resilience: Is it possible to improve stress resistance? Front Hum Neurosci 12: 326.

42. Kéri S (2009) Genes for psychosis and creativity: A promoter polymorphism of the neuregulin 1 gene is related to creativity in people with high intellectual achievement. Psychol Sci 20: 1070-1073.

43. Lut Van Laer, Huyghe JR, Hannula S, Eyken EV, Stephan DA, et al. (2010) A genome-wide association study for age-related hearing impairment in the Saami. Eur J Hum Genet 18: 685-693.

44. Cacabelos R, Fernández-Novoa L, Lombardi V, Carril JC, Corzo L, et al. (2011) Genomics of schizophrenia and psychotic disorders. Science 7-83.

45. Barnes A, Isohanni M, Barnett JH, Pietiläinen O, Veijola J, et al. (2012) No Association of COMT (Val158Met) Genotype with brain structure differences between men and women. PLoS One 7: e33964.

46. Stratinaki M, Varidaki A, Mitsi V, Ghose S, Magida J, et al. (2013) RGS4 regulates antidepressant drug actions. Proceedings of the National Academy of Sciences 110: 82548259 .
47. Walter EE, Fernandez F, Snelling M, Barkus E (2016) Genetic consideration of schizotypal traits A review. Front Psychol 7: 1769.

48. Jagannath V, Gerstenberg M, Walitza S, Franscini M, Heekeren K, et al. (2018) Neuregulin 1 (NRG1) gene expression predicts functional outcomes in individuals at clinical highrisk for psychosis. Psychiatry Res 266: 143-146.

49. Kiss ECS, Vajda D, Káplár M, Csókási K, Hargitai R, et al. (2015) A 25-items Connor-Davidson RezílienciaSkála (CDRISC) Magyaradaptációja. Mentálhigiénéés Pszichoszomatika 1: 93-113.

50. Southwick SM, Sippel L, Krystal J, Charney D, Mayes L, et al. (2016) Why are some individuals more resilient than others: The role of social support. World Psychiatry 15: 77-79.

51. Rosenberg M (1965) Society and the adolescent self-image. Princeton University Press.

52. Sallay V, Martos T, Földvári M, Szabó T, Ittzés A (2014) A Rosenberg ÖnértékelésiSkála (RSES-H): An alternative translation and structural invariance and validity. Mentálhigiénéés Pszichoszomatika 15: 259-275.

53. Baumeister RF, Campbell JD, Krueger JI, Vohs KD (2003) Does high self-esteem cause better performance, interpersonal success, happiness, or healthier lifestyles? Psychol Sci Pub Interest 4: 1-44.

54. Pyszczynsky T, Greenberg J, Solomon S, Arndt J, Schimel J (2004) Why do people need self-esteem? A theoretical and empirical review. Psychol Bull 130: 435-468.

55. Taylor SE, Stanton AL (2007) Coping resources, coping progress, and mental health. Ann Rev Clin Psychol 3: 377401.

56. Reiss S, Peterson RA, Gursky DM, McNally RJ (1986) Anxiety sensitivity, anxiety frequency, and the prediction of fearfulness. Behav Res Ther 24: 1-8.

57. Kerekes ZS (2012) A szorongás, mint adaptív viselkedés. A szorongásérzékenység mérésének tapasztatatai különböző csoportoknál. Ph.D. Disszertáció, Pécs PTE BTK.

58. Taylor S, Cox BJ (1998) Anxiety sensitivity: Multiple dimensions and hierarchic structure. Behav Res Ther 36: 37-51.

59. Deacon B, Abramowitz JS (2006) Anxiety sensitivity and its dimensions across anxiety disorders. J Anxiety Dis 20: 837-857.

60. Cohen AS, Mattewar R, Najolia G, Brown LA (2010) Toward a more psychometrically-sound brief measure of schizotypy improving the SPQ-Brief revised. J Per Dis 24: 516-537.

61. Raine A, Benishay D (1995) The SPQ-B: A brief screening instrument for schizotypal personality disorder. Journal of Personality Disorders, 9: 346-355.

62. Kállai J, Rózsa S, Hupuczi E, Hargitai R, Birkás B, et al. (2018) Schizotypy Personality Questionnaire Brief Revisited (SPQ-BR) Hungarian adaptation and interpretation of factors. Psychiatr Hung 33: 205-221.

63. Steptoe A (2007) Psychophysiological Contributions to Behavioral Medicine and Psychosomatics Cambridge. In: John T Cacioppo, Louis G Tassinary, Gary G Berntson, Handbook of Psychophysiology. ( $3^{\text {rd }}$ edn) University Press, New York, 723-751.

64. Brutsaert DL (2003) Cardiac endothelial-myocardial signaling: Its role in cardiac growth, contractile performance, and rhythmicity. Physiol Rev 83: 59-115.

65. Rupert CE, Coulombe KLK (2015) The roles of neuregulin-1 in cardiac development, homeostasis, and disease. Biomarker Insights 10: 1-9. 
66. Adélaïde J, Huang HE, Murati $A$, Alsop AE, Orsetti $B$, et al. (2003) A recurrent chromosome translocation breakpoint in breast and pancreatic cancer cell lines targets the neuregulin/NRG1 gene. Genes Chromosomes Cancer 37: 333-345.

67. Jonna S, Feldman RA, Swensen J, Gatalica Z, Korn WM, et al. (2019) Detection of NRG1 Gene Fusions in Solid Tumors. Clin Cancer Res 25: 4966-4972.

68. Hong CJ, Huo SJ, Liao DL, Lee K, Wu JY, et al. (2004) Case-control and family-based association studies between the neuregulin 1 (Arg38GIn) polymorphism and schizophrenia. Neurosci Lett 366: 158-161.

69. Kim JW, Lee YS, Cho EY, Jang YL, Park DY, et al. (2006) Linkage and association of schizophrenia with genetic vari- ations in the locus of neuregulin 1 in the Korean population. Am J Med Genet B Neuropsychiatr Genet 141: 281-286.

70. Mei L, Xiong WC (2008) Neuregulin 1 in neural development, synaptic plasticity, and schizophrenia. Nat Rev Neurosci 9: 437-452.

71. Sprooten E, Lymer GK, Maniega SM, J McKirdy, J D Clayden, et al. (2009) The relationship of anterior thalamic radiation integrity to psychosis risk associated neuregulin-1 variants. Mol Psychiatry 14: 237-238.

72. Mata I, Perez-Iglesias R, Roiz-Santiañez R, Tordesillas-Gutierrez D, Gonzalez-Mandly A, et al. (2009) A neuregulin 1 variant is associated with increased lateral ventricle volume in patients with first-episode schizophrenia. Biol Psychiatry 65: 535-540. 